\title{
Analysis on Screening Methods Of Key Sectors Of Industrial $\mathrm{CO}_{2}$ Emission
}

\author{
RAO Guang Ming 1,2, a , HU Xing \&YUAN Huan', b, WANG Yong ${ }^{1, c}$ \\ ${ }^{1}$ School of Economics \& Business Administration, Chongqing University, Chongqing 400030, China \\ ${ }^{2}$ Research Centre of Economy of Upper Reaches of the Yangtze River, School of Economics, \\ Chongqing Technology and Business University, Chongqing 400067, China \\ a2421149491@qq.com, b472662564@qq.com, c Corresponding author: wangyongkt@163.com
}

Keywords: Correlative effects, Key sectors, Industrial $\mathrm{CO}_{2}$ emission, Screening methods

Abstract. For reduction of industrial $\mathrm{CO}_{2}$ emission, sector $\mathrm{CO}_{2}$ emission reduction quotas should be fairly assigned based on their original $\mathrm{CO}_{2}$ emission level at sectors of industrial $\mathrm{CO}_{2}$ emission in the industrial chain, which bigger $\mathrm{CO}_{2}$ emitting sectors will be allocated more. But what are the bigger $\mathrm{CO}_{2}$ emitting sectors in input-output process of the industrial chain? This paper discusses the methodology of screening key sectors of industrial $\mathrm{CO}_{2}$ emission in the industrial chain by decomposing sector correlative effects of industrial $\mathrm{CO}_{2}$ emission into intermediate effect, terminal effect, spread effect and sensitivity, and establishes the relative formulation of measurements of the sector correlative effects of industrial $\mathrm{CO}_{2}$ emission including intermediate effect, terminal effect, spread effect and sensitivity.

\section{Introduction}

The Emission Gap Report 2013（the UNEP, 2013） says Current global greenhouse gas emission levels are considerably higher than the levels in 2020 that are in line with meeting the $1.5^{\circ} \mathrm{C}$ or $2^{\circ} \mathrm{C}$ targets to the pre-industrial level, and are still increasing. In absolute levels in 2010, developing countries accounted for about $60 \%$ of global greenhouse gas emission. Global emission levels estimated in 2025,2030 and 2050 consistent with the $2^{\circ} \mathrm{C}$ target amount to approximately $40 \mathrm{GtCO}_{2}$, $35 \mathrm{GtCO}_{2}$, and $22 \mathrm{GtCO}_{2}$ respectively. These levels are all based on the assumption that the 2020 least-cost level of $44 \mathrm{GtCO}_{2}$ estimated per year will be achieved.

On April 22, 2016, 175 countries gathered in the United Nations signed the Paris Agreement of the United Nations Framework Convention on Climate Change (UNFCCC) （the UN, 2016）, which is the third milestone in the history of global climate governance pattern after the United Nations framework convention on climate change in 1992 and the Kyoto protocol in 1997 for the human response to climate change. On November 4, 2016, the Paris Accord goes into effect, which has been clear for the national medium and long-term goals of $\mathrm{CO}_{2}$ emissions reduction to control the world $2{ }^{\circ} \mathrm{C}$ temperature rise targets in the year of 2020. It is indicated that green low carbon development is a global trend, which is creating a new round of global energy revolution and industrial revolution, is changing the mode of production and life of human society.

On November 4, 2016, the Chinese government issued the "13th five-year plan on control scheme for greenhouse gas emissions" （referred to as "the plan"）（The state council of China, 2016）, adhering to that priority is given to combining greenhouse gas emissions reduction with enhancing carbon sequestration ability and with carbon intensity drop target. With deepen development of low carbon economy, the plan proposes that $\mathrm{CO}_{2}$ emission will peak around 2030, and strive for the early peak; $\mathrm{CO}_{2}$ emission per industrial product is $22 \%$ lower than in 2015 , carbon intensity drops $60 \%$ to $65 \%$ lower than in 2005 , raise proportion of non-fossil energy to $20 \%$, adopt " 100 -kilometer $\mathrm{CO}_{2}$ emission" index as $\mathrm{CO}_{2}$ emission standards of new cars to promote green and low-carbon transformation of automobile industry. By 2020, $\mathrm{CO}_{2}$ emissions drop by $8 \%, 2.6 \%$ and $7 \%$ respectively lower than in 2015 in operation of truck, operating passenger car, revolving quantity of operation of ship. $\mathrm{CO}_{2}$ emissions for urban passenger transport per passenger drop to $12.5 \%$ lower 
than in 2015. The plan breaks down China national carbon intensity target to the provincial level, which in 2016-2020, Carbon intensity drop by $20.5 \%$ in Beijing, Tianjin, Hebei, Shanghai, Jiangsu, Zhejiang, Shandong and Guangdong respectively; drop 19.5\% in Fujian, Jiangxi, Henan, Hubei, Chongqing and Sichuan respectively; drop 18\% in Shanxi, Liaoning, Jilin, Anhui, Hunan, Guizhou, Yunnan and Shaanxi respectively; drop 17\% in Inner Mongolia, Heilongjiang, Guangxi, Gansu and Ningxia respectively; drop 12\% in Hainan, Tibet, Qinghai and Xinjiang respectively.

To reach this target, the government usually allocates $\mathrm{CO}_{2}$ emission reduction goals by industrial sector. It is essential that independent sectors are to be fairly assigned emission reduction quotas respectively based on their original $\mathrm{CO}_{2}$ emission level, which means the bigger $\mathrm{CO}_{2}$ emitting sectors will be allocated more quota. But how to filter the bigger $\mathrm{CO}_{2}$ emitting sectors from all the sectors in input-output process? This paper will discuss the correlative effects on the input and output of all relevant sectors' $\mathrm{CO}_{2}$ emission, and establish the methods of screening the key sectors by revealing associated and Spread degree of the cross-sector $\mathrm{CO}_{2}$ emission. Section 2 presents the literature review and Section 3 discusses methodology. Section 4 is conclusion.

\section{Literature Review}

Since the Input-output analysis（the IO approach）was introduced by Leontief（Leontief, 1951, 1986 ), it has been applied to numerous issues on economic development and $\mathrm{CO}_{2}$ emission from both production and final product perspectives.

Many researchers adopt the $\mathrm{IO}$ approaches to estimate the embodied $\mathrm{CO}_{2}$ emission in industry and trade based on the data derived from the input output table. Keisuke Nansai et al (2009) studied the embodied $\mathrm{CO}_{2}$ footprint of Japanese food products and general consumer goods from the end product consumer perspective with GLIO model (global link input-output). Thomas Wiedmann et al (2010) focused on the United Kingdom's embodied $\mathrm{CO}_{2}$ issue in international trade from 1992 to 2004. Chen Hong-min(2009) introduced the IO model to analyze the embodied $\mathrm{CO}_{2}$ emission in the final consumption and usage of products from each sector in China in 2002 including both the embodied $\mathrm{CO}_{2}$ emission from energy consumption as well as from industrial process. Wei Ben-yong et al(2009) evaluated $\mathrm{CO}_{2}$ emission embodied in China's import and export trade in 2002 with input-output table and sector energy consumption. Zhang Ji-lu (2012) did dynamic analysis on export embodied $\mathrm{CO}_{2}$ emission in China from 2002 to 2009 in the terms of total amount, industry and trading partners by developed input-output models.

Some researches focus on the direct and indirect $\mathrm{CO}_{2}$ emission or $\mathrm{CO}_{2}$ leakage in production chain by the modified IO approaches. Richard Wood and Christopher J. Dey（2009） analyzed $\mathrm{CO}_{2}$ footprint of 344 sectors in Australia in 2005 based on input-output analysis. Sun Jian-wei et al (2010) analyzed the direct and indirect $\mathrm{CO}_{2}$ emission of the products that are produced to meet the ultimate consumption of national economy, and studied the $\mathrm{CO}_{2}$ footprint and its relative links among each sector in China in 2002 by IOA-EF model. Ma Shu-zhong and Huang Dong-sheng (2011) analyzed the $\mathrm{CO}_{2}$ footprint of 55 countries and regions from 1995 to 2005 by MRIO model and identified a great $\mathrm{CO}_{2}$ leakage from developed countries to newly industrialized countries such as China. Yan Xia, et. al (2013) establishes an extended input-output (IO) model that calculates the cost multiplier transmission effect of emission reduction in low-carbon production chains.

Some studies focus analysis on intensity, correlative effects and spatial distribution of industrial $\mathrm{CO}_{2}$ emission by IO method. For instance, Cao Jun-wen (2011) estimated and analyzed direct $\mathrm{CO}_{2}$ intensity of industrial sectors and total $\mathrm{CO}_{2}$ intensity of industrial sectors in Jiangxi province by input-output model. Qian Ming-xia et al (2013) use hypothetical extraction method to calculate the total linkage effect, forward linkage effect and backward linkage effect of 11 industry groups in China in 2007, which is named as the internal effect, mixed effect, net backward effect and net forward effect respectively. Qi Shen-jun(2012) analyzed the tendency of direct energy consumption and spatial energy location, geographic distribution, and time-space distribution of $\mathrm{CO}_{2}$ emission, by working on annual energy consumption data in China's 30 provinces from 1995 to 2009. 
To be mentioned, the researches above by the IO approaches or modified discussed complex input and output relationships of $\mathrm{CO}_{2}$ emission existed amongst intermediated sectors, but do not reveal the main sectors and leading sectors of $\mathrm{CO}_{2}$ emission by research of correlative effects of industrial $\mathrm{CO}_{2}$ emission in the whole process of industrial chain. This paper will discuss sector correlative effects of industrial $\mathrm{CO}_{2}$ emission with empirical analysis of China's sample provinces of Chongqing, Shaanxi, Henan, Anhui, Beijing, Liaoning, and make sure which sectors are the main sectors and leading sectors of industrial $\mathrm{CO}_{2}$ emission with provincial spatial disparity.

\section{Methodology}

Conceptually from the whole process of the industrial chain, the sector correlative effects of industrial $\mathrm{CO}_{2}$ emission is a kind of combined effects of $\mathrm{CO}_{2}$ emission of an industry from angles of semiproduction, final use, and circumferential association. By the practical relevance of whole industrial development and $\mathrm{CO}_{2}$ emission, the sector correlative effects of industrial $\mathrm{CO} 2$ emission is defined as the distribution and impact of $\mathrm{CO}_{2}$ emission in the relevant sectors of the input-output table, and it can be further divided into intermediate effect, terminal effect, spread effect and sensitive effect based on industrial $\mathrm{CO}_{2}$ emission on the different steps of the input-output process. And so we can calculate and compare the $\mathrm{CO}_{2}$ emission of all relevant sectors of the industrial chain in input-output table and can screen the key sectors of industrial $\mathrm{CO}_{2}$ emission in the industrial chain, and by this we can disclose the difference of the relevance and impact of industrial $\mathrm{CO}_{2}$ emission of the alike industrial chain located in different regions.

\section{Intermediate Effect: Direct $\mathrm{CO}_{2}$ Emission Coefficient}

The intermediate effect refers to industrial $\mathrm{CO}_{2}$ emission of the sector $\mathrm{X}$ in the production of the intermediate relationship each unit value produced in the process of products directly produced by the primary energy consumption $\mathrm{CO}_{2}$ emission. It can be shown by Direct $\mathrm{CO}_{2}$ Emission Coefficient (the DCEC ), directly reflects the low $\mathrm{CO}_{2}$ production efficiency of industrial production of intermediate products. The value of the intermediate effect is that of each sector $\mathrm{CO}_{2}$ emission information transfer initial end of the whole national economy. The greater is the DCEC, the more is the industrial $\mathrm{CO}_{2}$ emission, and the lower is the low $\mathrm{CO}_{2}$ production efficiency.

It is defined as:

$$
c_{j}-\sum_{i=1}^{k} \frac{\overline{x_{u}}}{X_{j}} \quad(j-1,2, \cdots, n)
$$

Where: $c_{j}$ is the Direct $\mathrm{CO}_{2}$ Emission Coefficient, $\mathrm{K}$ is the number of the sectors, and $\mathrm{n}$ is the total number of sectors. $\overline{x_{1 j}}$ is the amount of $\mathrm{CO}_{2}$ emission directly generated by sector $\mathrm{j}$ consuming the output of sector $\mathrm{i}$, and $X_{\mathrm{i}}$ is the value of total product of sector $\mathrm{i}$.

\section{Terminal Effect: Total $\mathrm{CO}_{2}$ Emission Coefficient}

The terminal effect refers to industrial $\mathrm{CO}_{2}$ emission of the sector $\mathrm{X}$ in the production of the final use relating each unit production value of the final product, the $\mathrm{CO}_{2}$ emission generated from products and services when the whole society to provide the intermediate. It can be shown by Total $\mathrm{CO}_{2}$ Emission Coefficient (the TCEC), indirectly reflects the product life cycle efficiency based on the whole society's $\mathrm{CO}_{2}$ emission of the sector $\mathrm{X}$, which means the tracking of $\mathrm{CO}_{2}$ emission from industry sources through the production system to types of final demand.

$$
E=C(I+B)
$$

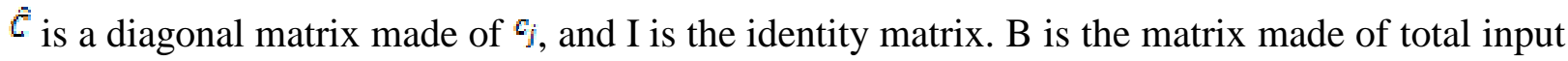
coefficient from input-output table. $\mathrm{E}$ is the square made of $e_{i j}$ which refers to the amount of $\mathrm{CO}_{2}$ emission per unit of final output generated by sector $\mathrm{j}$ consuming the output of sector $\mathrm{i}$.

Total $\mathrm{CO}_{2}$ emission coefficient $s_{j}$ is the sum of the column vector of $\theta_{i j}$, which is defined as: 


$$
s_{j}=\sum_{i=1}^{n} e_{i j} \quad(j=1,2, \cdots, n)
$$

The TCEC shows industrial $\mathrm{CO}_{2}$ emission embodied in the goods and services consumed by population. The greater is the TCEC, the more is the industrial $\mathrm{CO}_{2}$ emission, and the lower is the product life cycle efficiency based on the whole society's $\mathrm{CO}_{2}$ emission.

\section{Spread Effect: $\mathrm{CO}_{2}$ Emission Spread Coefficient}

The spread effect refers to the spread degree of industrial $\mathrm{CO}_{2}$ emission of the sector $\mathrm{X}$ in the input and output process every create one unit value product demand, the degree of industrial $\mathrm{CO}_{2}$ emission spread to the entire society. It can be shown by $\mathrm{CO}_{2}$ Emission Spread Coefficient (the CESC). It is defined as:

$$
F_{j}=\frac{\sum_{i=1}^{n} e_{i j}}{\frac{1}{n} \sum_{i=1}^{n} \sum_{j=1}^{n} e_{i j}} \quad(j=1,2, \cdots, n)
$$

The function can be improved by imitating the calculation method of Spread coefficient in input-output model. The greater the CESC is, the more Spread the sector $\mathrm{j}$ exerts over the total $\mathrm{CO}_{2}$ emission of the society. Generally over 1 of the CESC of the sector means obvious spread effect of industrial $\mathrm{CO}_{2}$ emission.

\section{Sensitive effect : $\mathrm{CO}_{2}$ Emission Inducing Coefficient}

The sensitive effect refers to the sensitive degree of industrial $\mathrm{CO}_{2}$ emission of the sector $\mathrm{X}$ in the whole process of input and output of the whole society to create one unit value of sensitivity of product requirements, the degree of industrial $\mathrm{CO}_{2}$ emission inducing from the entire society. It can be shown by $\mathrm{CO}_{2}$ Emission Inducing Coefficient（the CEIC）.

It is defined as:

$$
L_{i}=\frac{2_{j=1}^{7} \theta_{i j}}{\frac{1}{n} \sum_{i=1}^{n} \sum_{j=1}^{n} \theta_{i j}} \quad(j=1,2, \cdots, n)
$$

It also comes from the inducing coefficient in input-output model. The greater the CEIC is, the more sensitive the sector $\mathrm{i}$ is exerted by the society on industrial $\mathrm{CO}_{2}$ emission. Generally over 1 of the CEIC of the sector means obvious sensitive effect of industrial $\mathrm{CO}_{2}$ emission.

Screening key sectors of industrial $\mathrm{CO}_{2}$ emission

For the sake of screening the key sectors of industrial $\mathrm{CO}_{2}$ emission based on sector correlative effects, $\mathrm{CO}_{2}$ emission intensity and density are introduced as following.

\section{Regional $\mathrm{CO}_{2}$ emission intensity ( $\mathrm{RCI}$ )}

The $\mathrm{RCI}$ is defined as the ratio of regional $\mathrm{CO}_{2}$ emission and regional gross domestic products. It is used to measure the relationship between regional economic growth and $\mathrm{CO}_{2}$ emission.

It is defined as:

$$
I=\bar{X} / Y
$$

Where: $\mathrm{I}$ is for Regional $\mathrm{CO}_{2}$ emission intensity, $\bar{x}$ is for regional carbon emission, $\mathrm{Y}$ is gross regional product. At certain level of economic structure and the consumption structure of energy consumption, the smaller is the RCI, the stronger is the low-carbon economy development ability.

Industrial CO2 emission intensity (CEI)

The CEI reflects the sector's efficiency of industrial $\mathrm{CO}_{2}$ emission. the higher is the CEI, the higher is the sector's efficiency of industrial $\mathrm{CO}_{2}$ emission.

It is defined as:

$$
P_{j}=Y_{j} / \bar{X}_{j}
$$


Where: $P_{j}$ is for Industrial $\mathrm{CO}_{2}$ emission intensity; $\bar{x}_{j}$ is for sector $\mathrm{j}$ 's industrial $\mathrm{CO}_{2}$ emission of the region; $Y_{j}$ is for sector $\mathrm{j}$ 's gross product of the region, which can be shown as sector $\mathrm{j}$ 's industrial added value, or the final product value in the input-output table .

\section{Industrial $\mathrm{CO}_{2}$ emission density (CED)}

The $\mathrm{CED}$ is defined as the ratio of industrial $\mathrm{CO}_{2}$ emission intensity (CEI) and overall regional $\mathrm{CO}_{2}$ emission intensity ( $\mathrm{RCI}$ ), which directly reflects the relative differences of industrial $\mathrm{CO}_{2}$ emission efficiency of sectors in a region.

\section{Key sectors screening of industrial $\mathrm{CO}_{2}$ emission}

An sector with both greater than 1 of density of intermediate effect and density of terminal effect is defined as the major sector of industrial $\mathrm{CO}_{2}$ emission, which produces majority of industrial $\mathrm{CO}_{2}$ emission in local economy. And the one with both greater than 1 of spread effect and sensitive effect is defined as the leading sector of industrial $\mathrm{CO}_{2}$ emission, which plays a key role in local industrial $\mathrm{CO}_{2}$ emission system.

\section{Conclusion}

This paper discusses the methodology of screening the key sectors of industrial $\mathrm{CO}_{2}$ emission in the industrial chain. Conceptually from the whole process of the industrial chain, the sector correlative effects of industrial $\mathrm{CO}_{2}$ emission is defined as combined effects of $\mathrm{CO}_{2}$ emission of an industry from angles of semiproduction, final use, and circumferential association. It can be further divided into intermediate effect, terminal effect, spread effect and sensitive effect based on industrial $\mathrm{CO}_{2}$ emission on the different steps of the input-output process. We can calculate and compare the $\mathrm{CO}_{2}$ emission of all relevant sectors of the industrial chain in input-output table and can screen the key sectors of industrial $\mathrm{CO}_{2}$ emission in the industrial chain, and by this we can disclose the difference of the relevance and impact of industrial $\mathrm{CO}_{2}$ emission of the alike industrial chain located in different regions.

\section{Acknowledgment}

This paper is financially supported by the National Social Science Foundation of China under grant 17AJY006.

This paper is funded by the key research base of humanities and social science of Ministry of Education of China under grant15JJD790043.

\section{References}

[1] Cao. J. W. (2011). Characteristics of Jiangxi's industrial sector $\mathrm{CO}_{2}$ emission intensity and $\mathrm{CO}_{2}$ reduction approach----input-output analysis based on the 1992 to 2007. Economic Geography, 31(12):2111-2115.

[2] Chen, H. M. (2009). Analysis on embodied $\mathrm{CO}_{2}$ emission including industrial process emission. Chinese Journal of Population Resources and Environment, 19(3), 25-30.

[3] Dongsheng, M. S. H. (2011). A cross-country study of $\mathrm{CO}_{2}$ footprint using mrio model. Chinese Journal of Zhejiang University (Humanities and Social Sciences), 42(4),5-15.

[4] Leontief, WW (1951). The Structure of the American Economy. New York: Oxford University Press.

[5] Leontief, WW (1986). Input-Output Economics (2nd ed). New York: Oxford University Press.

[6] Nansai, K., Kagawa, S., Kondo, Y., Suh, S., Inaba, R., \& Nakajima, K. (2009). Improving the completeness of product $\mathrm{CO} 2$ footprints using a global link input-output model: the case of Japan. Economic Systems Research, 21(3), 267-290. 
[7] Qi,S.J., Zhang,Y.B. \& Dong,X.Y. (2012).Characteristics of Construction Industry Relevancy and Industry Spread. Journal of Wut (Information Management Engineering), 34(5): 596-600.

[8] Qian,M.X.,Lu,Z.N. \& Wang, J. (2013).Analysis of Linkage of $\mathrm{CO}_{2}$ emission in Industrial Sectors Based on Hypothetical Extraction Method. Chinese Journal of Population,Resources and Environment, 23(9), 34-41.

[9] Sun.J.W., Chen.Z.G.,Zhao.R.Q.\& Lai.L. (2010). Research on $\mathrm{CO}_{2}$ emission footprint of china based on input-output model. Chinese Journal of Population, Resources and Environment, 20(5), 28-34.

[10] The Global Commission on The Economy And Climate. The New Climate Economy Report 2014. https://www.gov.uk/government/news/new-climate-economy-report.

[11] The United Nations Environment Program (UNEP). The Emissions Gap Report 2013. A UNEP Synthesis Report. https://www.transparency-partnership.net/sites/default/files/unep 2013-theemissionsgapreport2013.pdf

[12] The state council of China. the 13th five-year plan on control scheme for greenhouse gas emissions. http://www.gov.cn/zhengce/content/2016-11/04/content_5128619.htm

[13] The United Nations. the Paris Agreement of the United Nations Framework Convention on Climate Change (UNFCCC). http://unfccc.int/paris_agreement/items/9485.php

[14] Wei,B.Y., Fang,X.Q., Wang.Y., Yang.H.M, \& Zhang.D. (2009).Estimation of $\mathrm{CO}_{2}$ emission embodied in international trade for china: an input- output analysis. Chinese Journal of Beijing Normal University(Natural Science), 45(4):413-419

[15] Wiedmann, T., Wood, R., Minx, J. C., Lenzen, M., Guan, D., \& Harris, R. (2010). A CO 2 footprint time series of the UK-results from a multi-region input-output model. Economic Systems Research, 22(1), 19-42.

[16] Wood, R., \& Dey, C. J. (2009). Australia's $\mathrm{CO}_{2}$ footprint. Economic Systems Research, 21(3), 243-266.

[17] Yan Xia, Ying Fan and Jie Wu. Analysis of low-carbon production chains towards China's $\mathrm{CO}_{2}$ emission reduction targets for 2020. The Singapore Economic Review, Vol. 58, No. 3 (2013) 1350021 (18 pages) (C) World Scientific Publishing Company.

[18] Zhang. J. L. (2012). Research on embodied $\mathrm{CO}_{2}$ emission of China's export trade --based on an input-output model. Research on Financial and Economic Issues, 344(7):112-117. 